\title{
Pore Structure of Calcium Sulfoaluminate Paste and Durability of Concrete in Freeze-Thaw Environment
}

\author{
Kyle de Bruyn"), Eric Bescher ${ }^{2}$, Chris Ramseyer ${ }^{3)}$, Seongwon Hong ${ }^{4), *}$, and \\ Thomas H.-K. Kang ${ }^{5}$
}

(Received April 9, 2016, Accepted September 30, 2016, Published online December 1, 2016)

\begin{abstract}
Mercury intrusion and nitrogen sorption porosimetry were employed to investigate the pore structure of calcium sulfoaluminate $(C \bar{S} A)$ and portland cement pastes with cement-to-water ratio (w/c) of $0.40,0.50$, and 0.60 . A unimodal distribution of pore size was drawn for $C \bar{S} A$ cement pastes, whereas a bimodal distribution was established for the portland cement pastes through analysis of mercury intrusion porosimetry. For the experimental results generated by nitrogen sorption porosimetry, the $C \bar{S} A$ cement pastes have a smaller and coarser pore volume than cement paste samples under the same w/c condition. The relative dynamic modulus and percentage weight loss were used for investigation of the concrete durability in freeze-thaw condition. When coarse aggregate with good freeze-thaw durability was mixed, air entrained portland cement concrete has the same durability in terms of relative dynamic modulus as $C \bar{S} A$ cement concrete in a freeze-thaw environment. The $C \bar{S} A$ cement concrete with poor performance of durability in a freeze-thaw environment demonstrates the improved durability by $300 \%$ over portland cement concrete. The $C \bar{S} A$ concrete with good performance aggregate also exhibits less surface scaling in a freeze-thaw environment, losing $11 \%$ less mass after 297 cycles.
\end{abstract}

Keywords: calcium sulfoaluminate cement, freeze-thaw environment, mercury intrusion porosimetry, nitrogen sorption porosimetry, portland cement

\section{Introduction}

A water-to-cement ratio (w/c) of approximately 0.25 would be sufficient to completely hydrate the compounds based on the examination of the stoichiometry of the reactions for portland cement. However, in practice this is rarely the case. At such a water-cement ratio in cement concrete, one obtains a very poor mixture that is very stiff and nearly impossible to work with. Therefore, additional water is added to the concrete to facilitate mixing and workability, and a w/c of 0.40 to 0.60 is generally chosen. As the cement begins to hydrate, the paste begins to harden. Because not all of the water is used up in the

\footnotetext{
${ }^{1)}$ Vesuvius, Pittsburgh, PA, USA.

${ }^{2)}$ Department of Materials Science and Engineering, University of California at Los Angeles, Los Angeles, CA, USA.

${ }^{3)}$ School of Civil Engineering and Environmental Science, University of Oklahoma, Norman, OK, USA.

${ }^{4)}$ Engineering Research Institute, Seoul National University, Seoul, Korea.

*Corresponding Author; E-mail: shong@snu.ac.kr

${ }^{5)}$ Department of Architecture and Architectural Engineering, Seoul National University, Seoul, Korea.

Copyright ( $\odot$ The Author(s) 2016. This article is published with open access at Springerlink.com
}

reaction, channels and capillaries of water are left over weaving through the hydrated paste. These make up the largest and most continuous pores in cement pastes and generally control the transport of substances through the cement matrix. The developed pores in cement hydrations play a significant role in their mechanical behaviors and durability.

Powers (1958) was considered the pioneer who investigated the porosity of portland cement pastes and developed a simplified model of the microstructure of portland cement paste based on water vapor adsorption, water fixation, and total porosity measurements. According to the works of Powers (1958), the calcium silicate hydrate $(\mathrm{C}-\mathrm{S}-\mathrm{H})$ phase could be modeled as a mass of colloidal spheres with a hexagonal closepacked arrangement, based on a calculated porosity of $26 \%$. The micropores in between the spherical $\mathrm{C}-\mathrm{S}-\mathrm{H}$ particles were gel pores and the water in these pores was strongly bound and could not be evaporated easily from the paste. The macropores between larger groups' spheres were capillary pores and water was much more easily evaporated from these pores. Other models for the $\mathrm{C}-\mathrm{S}-\mathrm{H}$ structure have also been proposed such as variations on the gel and capillary pore ideas (Feldman and Sereda 1970; Wittmann 1977; Jennings and Tennis 1995). All of the theories are based on the idea of the $\mathrm{C}-$ $\mathrm{S}-\mathrm{H}$ phase possessing a few alternating layers of particles and chemically bound water. The gel pores lie in between the layers. Small units of the layered structures are then randomly distributed in the cement matrix, with the capillary pores existing in the spaces between the units. 
Calcium sulfoaluminate $(C \bar{S} A)$ cement is manufactured in a similar way to portland cement, but with limestone, clay, and gypsum, and burned at a lower temperature [approximately $\left.1300{ }^{\circ} \mathrm{C}\left(2400{ }^{\circ} \mathrm{F}\right)\right]$ in the cement kiln. The greatest chemical difference between $C \bar{S} A$ and portland cements is the alumina content, which is much higher in $C \bar{S} A$ cement. The $C \bar{S} A$ cement gains early strength by the generation of ettringite. The generation of ettringite begins almost immediately after the addition of water to the system and is generally complete after several hours. The shape ettringite is in the form of needle-like crystals, which create a crystalline network within the cement matrix. After the compounds have completed their transformation to ettringite, a longer term reaction of the belite $\left(\beta-\mathrm{C}_{2} \mathrm{~S}\right.$, dicalcium silicate) phase into C-S-H continues for months (Ost 1975). Recently, newer technologies such as the use of $C \bar{S} A$ cement are increasingly popular for post-tensioned concrete floor structures because of the shrinkage-compensating characteristics and other advantages (Han et al. 2006; Kang et al. 2009; Yang and Kang 2011; Bondy 2011; Jeon et al. 2015; Lee et al. 2016).

However, very little research has been conducted on the porosity of $C \bar{S} A$ based cement. There is one published paper where the porosimetric features of $C \bar{S} A$ and portland cements were analyzed as they changed with time during the hydration process (Bernardo et al. 2006). Mercury intrusion porosimetry was employed to measure the pore volume and size distribution. Although the unique pore structure of $C \bar{S} A$ cement paste related to its early strength properties, relative impermeability, chemical resistance, and other engineering properties was extensively investigated, the analysis of porosity of $C \bar{S} A$ cement was not enough to fully understand the pore size distribution because other pore analysis techniques to provide data on pore diameters smaller than $10 \mathrm{~nm}$, which can provide valuable insight into the microstructure of $C \bar{S} A$ cement paste, were required.

The purpose of this paper is (1) to examine the pore structures of $C \bar{S} A$ cement and portland cement pastes by mercury intrusion and nitrogen sorption porosimetry, and (2) to analyze the relative performance of concrete made with $C \bar{S} A$ and portland cement in a freezing and thawing environment.

\section{Experimental Methods}

\subsection{Materials, Preparations, and Experimental Procedures}

A $C \bar{S} A$ cement is manufactured by CTS Cement Manufacturing Corporation, and a commercial cement, Type II/V portland cement, is provided from Riverside Cement Company. An oxide analysis of both types of cement was obtained via X-ray fluorescence (XRF) and summarized in Table 1.

The $C \bar{S} A$ and portland cements were employed with a Blanine fineness (ASTM C204) of approximately 6400 and $4100 \mathrm{~cm}^{2} / \mathrm{g}$, respectively. According to the ASTM C109 procedures, the compressive strength of the $C \bar{S} A$ and portland cement mortar was measured at $1 \mathrm{~h}, 3 \mathrm{~h}, 1$ day, 3 days, 7 days, and 28 days and the experimental results are given in Table 2.

The $C \bar{S} A$ and portland cement paste specimens were conducted with w/c of $0.40,0.50$, and 0.60 . An iced water with a temperature of $0.6{ }^{\circ} \mathrm{C}$ was used for the $C \bar{S} A$ cement paste because the $C \bar{S} A$ cement paste has a tendency to hydrate very quickly. Each paste specimen had a diameter of $5.08 \mathrm{~cm}$ and a length of $1.27 \mathrm{~cm}$. The molds were covered with a plastic sheet and left to cure under laboratory conditions for 3 days, at which time the specimens were stripped from the molds and cured in lime saturated water for 28 days. After curing, the samples were weighed and placed in a sealed plastic container with approximately $1 \mathrm{~kg}$ of anhydrous silica gel. The weight of each specimen was periodically measured to determine the degree of desiccation. All of the specimens were stored in the desiccation box for 56 days, at which point the weight change per day was less than $0.02 \%$ because an appropriate level of desiccation for cement pastes was required for nitrogen pore analysis.

For the mercury intrusion analysis, the samples were broken into pieces less than $2 \mathrm{~cm}$ in diameter, which is the largest the mercury intrusion device could accommodate. For portland cement, grinding the sample to smaller sizes showed an additional porosity in the $1 \mu \mathrm{m}$ range that was not present in larger samples. Therefore, the specimens were not ground in the same manner as for the nitrogen sorption test so that surface effects and microcracking of the cement matrix could be avoided. Analysis was conducted in a PMI Instruments Mercury Intrusion Porosimeter at PMI, Inc., Ithaca, NY.

For the nitrogen sorption analysis, the specimens were broken into small pieces and then ground using a mortar and pestle to pass a \#16 sieve (1190 $\mu \mathrm{m}$ spacing). The materials were then screened on a \#30 sieve (595 $\mu \mathrm{m}$ spacing) and the retained materials were used for the analysis. The ground and screened material samples were analyzed in a Micromertitics ASAP 2010. Surface area calculations were performed according to the Brunauer-Emmett-Teller (BET) theory (Brunauer et al. 1938) and t-plot by Harkins-Jura (Harkins and Jura 1944), and pore size distribution was determined by the Barrent-Joyner-Halenda (BJH) theory (Barrett et al. 1951).

For the concrete freeze-thaw tests, two types of limestone obtained from the state of Missouri were selected based on supplier reports of freeze-thaw performance. One limestone (Limestone $\mathrm{G}$ ) was reported to have very good performance in a freezing and thawing environment, while the other (Limestone B) was reported to have very poor performance in a freezing and thawing condition. Both types of limestone were tested for their porosity characteristics using the same procedure as the hardened cement pastes. These two types of limestone were combined with $C \bar{S} A$ or portland cement, sand, water, and an air-entraining admixture to create concretes typical of early strength designs. Each batch was mixed and specimens molded according to the procedures in the ASTM C192. The specific mix designs and resulting plastic concrete properties are summarized in Table 3. 
Table 1 Chemical compositional analysis by XDF (mass \%).

\begin{tabular}{c|c|r}
\hline Composition & $C \bar{S} A$ cement & Portland cement \\
\hline $\mathrm{SiO}_{2}$ & 11.47 & 3.23 \\
\hline $\mathrm{AI}_{2} \mathrm{O}_{3}$ & 11.40 & 3.85 \\
\hline $\mathrm{Fe}_{2} \mathrm{O}_{3}$ & 0.98 & 55.18 \\
\hline $\mathrm{CaO}$ & 36.71 & 2.48 \\
\hline $\mathrm{MgO}$ & 2.67 & 8.67 \\
\hline $\mathrm{SO}_{3}$ & 9.99 & 0.04 \\
\hline $\mathrm{Na}_{2} \mathrm{O}$ & 0.04 & 0.27 \\
\hline $\mathrm{K}_{2} \mathrm{O}$ & 0.31 & 5.36 \\
\hline $\mathrm{C}_{4} \mathrm{~A}_{3} \overline{\mathrm{S}}$ & 21.69 & - \\
\hline $\mathrm{CS}$ & 4.74 & \\
\hline
\end{tabular}

Table 2 Compressive strength of calcium sulfoaluminate and portland cement mortar, MPa.

\begin{tabular}{c|c|c|c|c|c|c}
\hline & 1 Hour & 3 Hours & 1 Day & 3 Days & 7 Days & 28 Days \\
\hline \hline$C \bar{S} A$ cement & 38.3 & 41.1 & 56.9 & 58.1 & 60.2 & 62.1 \\
\hline Portland cement & - & - & 8.9 & 21.5 & 28.4 & 40.0 \\
\hline
\end{tabular}

Table 3 Proportions and properties of concrete mixture for freeze-thaw tests.

\begin{tabular}{c|c|c|c|c}
\hline & \multicolumn{2}{|c|}{$C \bar{S} A$} & \multicolumn{2}{c}{ Portland } \\
\cline { 2 - 5 } & Limestone G & Limestone B & Limestone G & 477.5 \\
\hline \hline Cement (kg) & 420.8 & 420.8 & 477.5 & 764.0 \\
\hline Fine aggregate (kg) & 764.0 & 764.0 & 764.0 & 1091.0 \\
\hline Coarse aggregate (kg) & 1021.2 & 1091.0 & 1021.2 & 225.0 \\
\hline Water (kg) & 198.2 & 198.2 & 0.4999 & 0.4999 \\
\hline $\begin{array}{c}\text { Air entraining admixture } \\
(\mathrm{kg})\end{array}$ & 0.4102 & 0.4102 & 18 & 17 \\
\hline Slump (cm) & 15 & 15 & 5.5 & 6.0 \\
\hline Air content (\%) & 6.0 & 6.5 & & \\
\hline
\end{tabular}

Three concrete beams were cast for each mix design for freeze-thaw testing. The dimension of each beam was $7.6 \mathrm{~cm} \times 7.6 \mathrm{~cm} \times 29.2 \mathrm{~cm}$. They were cured in the molds under a polyethylene sheet for $24 \mathrm{~h}$, then stripped and cured in lime saturated water for 14 days, in accordance with the standard ASTM C666. After curing in water, the beams were transferred to individual rigid sheet metal containers which were then filled with water to just above the specimen surface, and placed in a freeze-thaw chamber. The chamber was temperature controlled and automated to cycle between -18 and $4{ }^{\circ} \mathrm{C}$. The temperature was recorded in the middle of a dummy concrete specimen by an embedded thermocouple. During the course of the test, the machine was automatically able to cycle about 5 to 6 times per day. The specimens were periodically removed from the chamber, patted dry with a towel, weighed, and measured fundamental transverse frequency using the impact method as described in ASTM C215 and Olson Instruments RT-1 resonance tester. The relative dynamic modulus (RDM) for each specimen was calculated from the fundamental transverse frequency using the following equation supplied by Olson Instruments:

$$
\mathrm{RDM}=\frac{f_{n}^{2}}{f_{0}^{2}} \times 100 \%
$$

where $f_{0}$ is the fundamental transverse frequency measured at zero cycles and $f_{n}$ is the fundamental transverse frequency measured at $n$ cycles.

After measuring the frequency, the specimens were returned to the rigid containers which were refilled with fresh water. The containers were then returned to the freezethaw chamber. If any specimen was damaged from freezethaw to the point where a fundamental transverse frequency could not be measured, the set was declared to have failed and removed from further testing. 


\section{Results and Discussion}

\subsection{Specimen Drying}

Figure 1 and Table 4 show the drying measurement of the specimens. In Fig. 1a, the percent weight loss was very similar between $C \bar{S} A 0.50$ and $\mathrm{PC} 0.40$, and between $C \bar{S} A$ 0.60 and $\mathrm{PC} 0.50$. This is an indication of difference in the quantity of water which was chemically bound to the hydrated products in both types of cement. For instance, the $C \bar{S} A$ cement chemically binds with about $25 \%$ more water than portland cement, which is potentially the pore volume by a similar amount. Therefore, a $C \bar{S} A$ cement paste with a $\mathrm{w} / \mathrm{c}$ of 0.50 has about the same water-intrudable pore volume as a portland cement paste with a w/c of 0.40 . Because $C \bar{S} A$ 0.50 and PC 0.40 lost approximately the same volume of water through evaporation, it is notable that the $C \bar{S} A 0.50$ lost its water at a much faster rate in the first 21 days, as exhibited in Fig. 1b. This signifies that water was evaporated more readily from the $C \bar{S} A$ cement sample than the portland cement sample. As a result, the pore structure would be coarser and straighter in the $C \bar{S} A$ cement paste than the portland cement paste.

\subsection{Mercury Intrusion Porosimetry}

Table 5 demonstrates the pore volume and surface area data estimated by the mercury intrusion porosimetry. The $C \bar{S} A$ cement pastes have a larger threshold pore size and critical pore size than the portland cement samples given in the same w/c, excluding w/c ratio 0.40 . Figure 2 shows the pore size distribution of two cement pastes. The $C \bar{S} A$ cement samples showed a flattened shoulder (unimodal) in the same pore size region in Fig. 2b, while the portland cement pastes had a small secondary peak (bimodal) between 10 and $20 \mathrm{~nm}$ in Fig. 2d. The mercury intrusion analysis implies that the pore structure of the $C \bar{S} A$ cement paste is coarser than that of the portland cement paste in the same w/c. The total volume of intrudable mercury increases with increasing $\mathrm{w} / \mathrm{c}$ for both cement pastes. Because not all of the water in the cement paste was employed to hydrate the reactants, capillaries were left over once the matrix was hardened. The more water is present in the system at the beginning, the more pore space remains open after hydration has completed. The critical pore diameter, which is the highest value of DV/Dlog(D) in Fig. 2b, shows that $C \bar{S} A$ cement has a larger critical pore diameter than portland cement for the same w/c. The test result for the threshold pore diameter is similar in trend, as shown in Table 5. These two results support that the overall pore structure of $C \bar{S} A$ cement is coarser than the pore structure of portland cement for pore diameters between $3 \mathrm{~nm}$ and $10 \mu \mathrm{m}$.

The $C \bar{S} A$ cement pastes exhibited lower total surface area than the portland cement pastes for all $\mathrm{w} / \mathrm{c}$ ratios (see Table 5). This is partially indicative of a coarser pore structure, and could be related to the degree of hydration of the cement. It is possible that the $\beta-\mathrm{C}_{2} \mathrm{~S}$ phase in the $C \bar{S} A$ cement does not hydrate as completely as the $\mathrm{C}_{2} \mathrm{~S}$ and $\mathrm{C}_{3} \mathrm{~S}$ phases in portland cement because the water is very quickly taken up by the ettringite reaction, reducing the overall porosity and slowing the ingress of curing water. Based on the median and average pore diameters in Table 5, it was decisively concluded that there exists coarser pore structure in $C \bar{S} A$ cement paste than in portland cement paste for the same $\mathrm{w} / \mathrm{c}$.

Figure 3 demonstrates pore size distributions and cumulative pore volume charts, and mercury intrusion analysis of the limestone samples showed marked difference between the two samples tested. Limestone $G$ was much less porous and contained smaller pores than Limestone B. Limestone $G$ had essentially no measureable pores larger than $30 \mathrm{~nm}$, where Limestone B had considerable porosity up to $2000 \mathrm{~nm}$.

\subsection{Nitrogen Sorption of Cement Pastes}

The pore volume and surface area were summarized in Table 6. The nitrogen sorption pore analysis for all samples

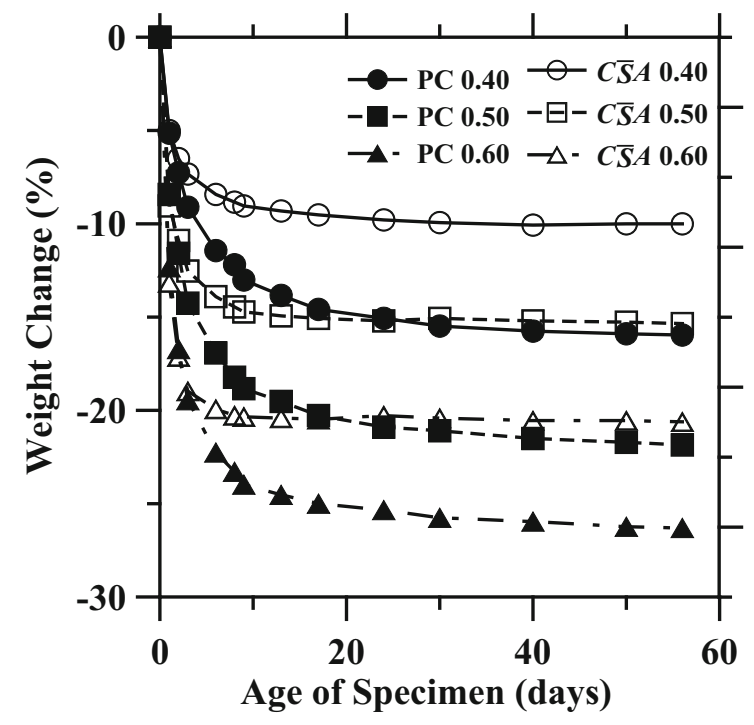

(a) Drying percentage weight change

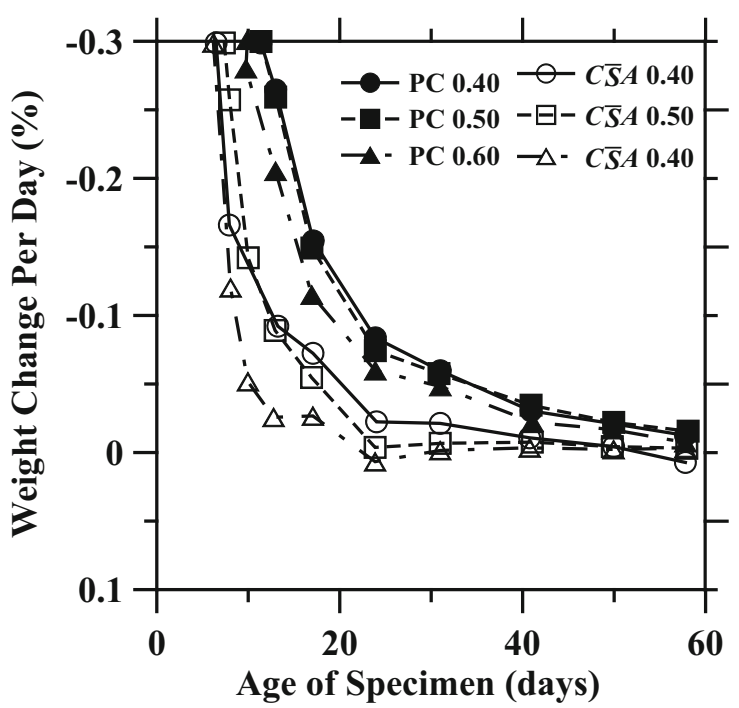

(b) Weight change per day

Fig. 1 Percent weight change and rate of weight change of the portland and $C \bar{S} A$ cement pastes. 
Table 4 Drying characteristics of the $C \bar{S} A$ and portland cement pastes.

\begin{tabular}{c|c|c}
\hline Mixture ID & Total \% weight change & Day to equilibrium (less than 0.02 \%/day) \\
\hline$C \bar{S} A 0.4^{\mathrm{a}}$ & -9.9 & 24 days \\
\hline$C \bar{S} A 0.5$ & -15.3 & 24 days days \\
\hline$C \bar{S} A 0.6$ & -20.3 & 50 days \\
\hline PC $0.4^{\mathrm{b}}$ & -15.9 & 50 days \\
\hline PC 0.5 & -21.7 & 41 days \\
\hline PC 0.6 & -26.0 & \\
\hline
\end{tabular}

a The mixture ID $C \bar{S} A 0.40$ stands for the $C \bar{S} A$ cement pastes or concrete with a water-to-cement ratio of 0.4 .

b The mixture ID PC 0.40 stands for the portland cement pastes or concrete with a water-to-cement ratio of 0.4 .

Table 5 Pore volume and surface area data determined by mercury intrusion porosimetry.

\begin{tabular}{c|c|c|c|c|c|c}
\hline & \multicolumn{3}{|c|}{$C \bar{S} A$} & & \multicolumn{2}{c}{ Portland } \\
\hline w/c & 0.4 & 0.5 & 0.6 & 0.4 & 0.5 & 0.1903 \\
\hline $\begin{array}{c}\text { Total pore volume } \\
\left(\mathrm{cm}^{3} / \mathrm{g}\right)\end{array}$ & 0.0822 & 0.1109 & 0.2014 & 0.0738 & 0.3031 \\
\hline $\begin{array}{c}\text { Critical diameter } \\
D_{\text {crit }}(\mathrm{nm})\end{array}$ & 34 & 96 & 185 & 2350 & 107 \\
\hline $\begin{array}{c}\text { Threshold pore } \\
\text { diameter } D_{\text {th }}(\mathrm{nm})\end{array}$ & 79 & 141 & 657 & 11 & 154 & 530 \\
\hline $\begin{array}{c}\text { Total surface area } \\
\left(\mathrm{m}^{2} / \mathrm{g}\right)\end{array}$ & 13.7 & 11.78 & 16.02 & 18.44 & 29.13 & 32.05 \\
\hline $\begin{array}{c}\text { Median pore } \\
\text { diameter (nm) }\end{array}$ & 35 & 64 & 118 & 1874 & 51 & 93 \\
\hline $\begin{array}{c}\text { Standard deviation } \\
(\mathrm{nm})\end{array}$ & 14 & 22 & 25 & 10 & 13 & 17 \\
\hline $\begin{array}{c}\text { Average pore } \\
\text { diameter (nm) }\end{array}$ & 29 & 43 & 53 & 24 & 26 & \\
\hline
\end{tabular}

reveals a hysteresis loop of type $\mathrm{H} 3$ as classified by the International Union of Pure and Applied Chemistry (IUPAC) (Lowell et al. 2004). According to Lowell et al. (2004), this type of loop is observed with non-rigid aggregates of platelike particles giving rise to slit-shaped pores. For surface area data in Table 6 , the $C \bar{S} A$ cement showed decrease in area with increasing $\mathrm{w} / \mathrm{c}$, while the portland cement exhibited that area increases with increasing w/c. In general, the surface area of a cement paste increases with increasing degree of hydration and the rate of hydration depends on the w/c (Cook and Hover 1999, Juenger and Jennings 2001). Therefore, higher w/c portland cement pastes have higher surface areas for the same amount of curing time. The present study confirms this trend. However, for $C \bar{S} A$ cement paste, the opposite trend was observed.

The total pore volume and pore size distribution were calculated by using desorption curve, the BET theory, the Harkins-Jura t-curve, and the BJH theory (Barrett et al. 1951). The pore size distributions and cumulative pore volumes are given in Fig. 4. The results indicate that in the range of pore sizes between 3 and $200 \mathrm{~nm}$ the portland cement paste samples have a greater overall pore volume than the $C \bar{S} A$ cement pastes under the same w/c ratio condition. The $C \bar{S} A$ cement samples showed a very strong pore size peak between 3 and $4 \mathrm{~nm}$, which was not present in the portland cement paste samples, whereas the portland cement samples showed a peak pore size between 10 and $20 \mathrm{~nm}$. In Fig. 4, it is clear that nearly half the measured surface area in the $C \bar{S} A$ cement pastes is from pores smaller than $4 \mathrm{~nm}$ in diameter. There is a trend where $C \bar{S} A 0.6$ has the fewest pores in this region while $C \bar{S} A 0.4$ has the most. These small differences in the pore size distribution lead to much larger differences in the total surface area of each paste, and this is apparently the reason for the surface area versus water-cement ratio trend in the $C \bar{S} A$ cement paste.

Comparing the pore size distributions of portland cement and $C \bar{S} A$ cement for the same w/c indicates that the $C \bar{S} A$ cement paste appears to have an overall coarser pore structure with more pores in the $30-50 \mathrm{~nm}$ range than the portland cement paste, but much greater porosity in the range below $5 \mathrm{~nm}$. The presence of ettringite may play a role in this enhanced microporosity, in the form of large defects in the crystalline ettringite, or voids in the ettringite crystals.

The nitrogen sorption measurements for the PC 0.40 sample appeared unusual; e.g., the surface area was significantly lower than the PC 0.50 or PC 0.60 samples, as was 


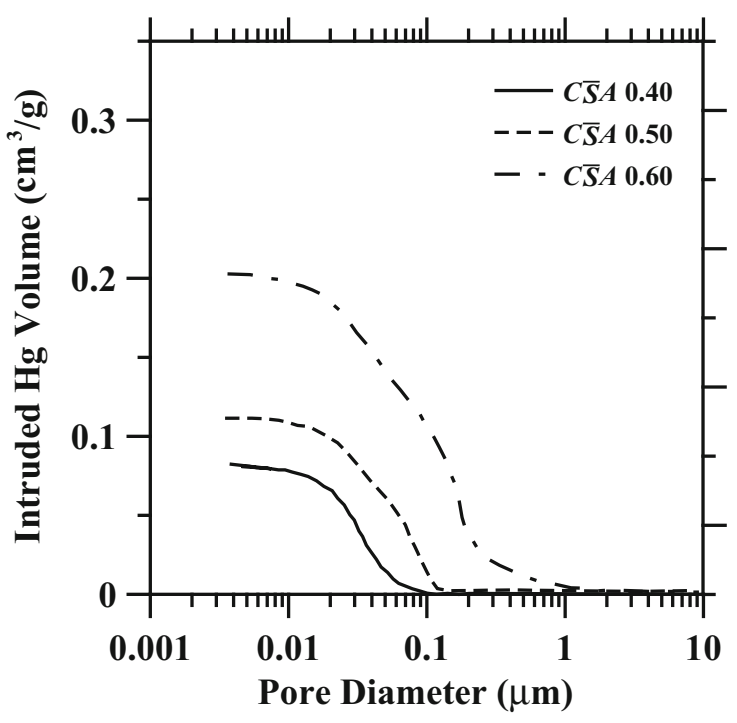

(a) $C \bar{S} A$ cement, cumulative plot

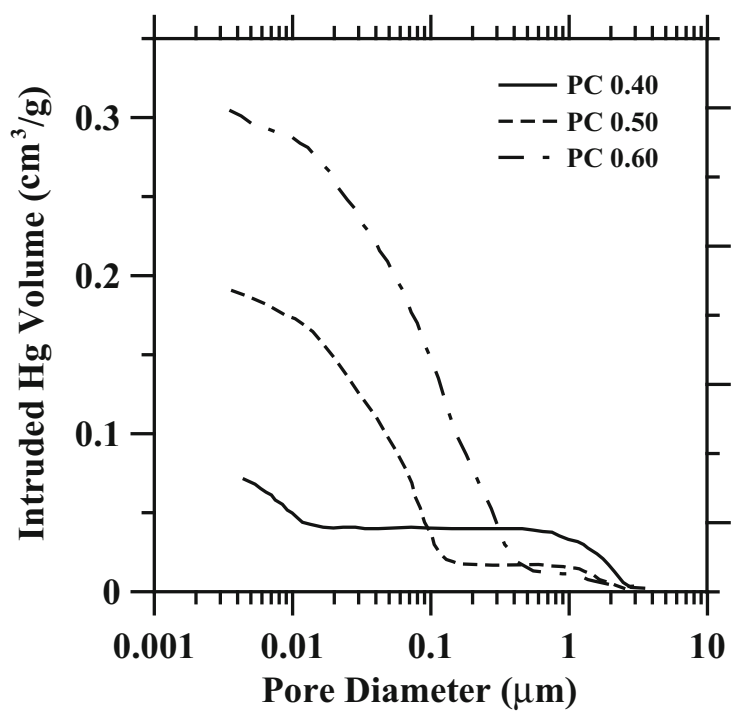

(c) Portland cement, cumulative plot

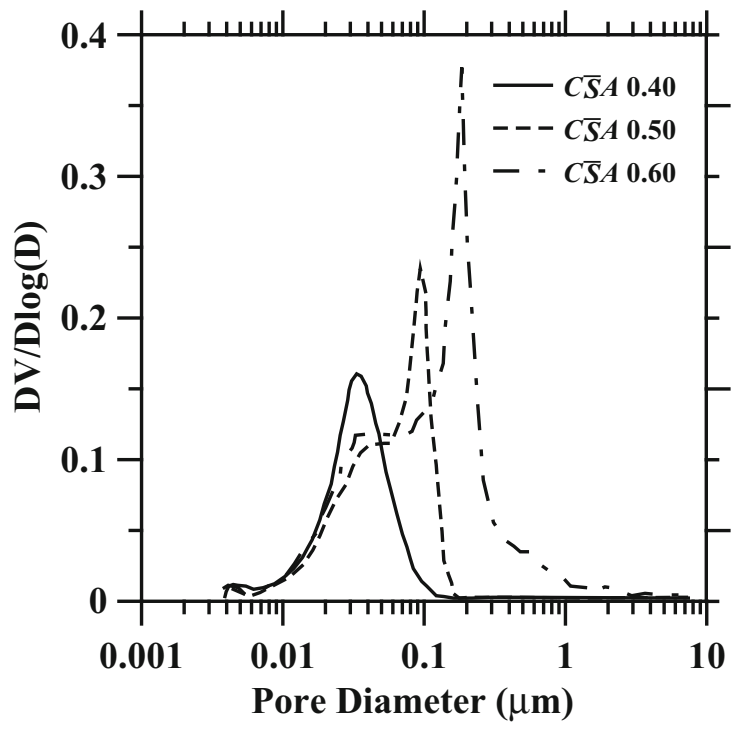

(b) $C \bar{S} A$ cement, derivative plot

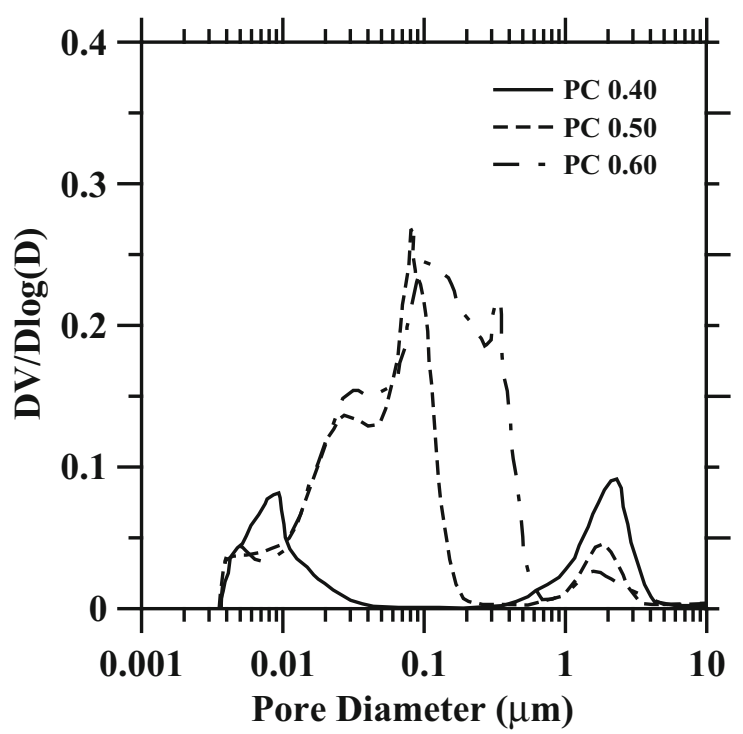

(d) Portland cement, derivative plot

Fig. 2 Intruded $\mathrm{Hg}$ volume versus pore radius for cement pastes.

the total pore volume. It is possible that for this particular portland cement at $\mathrm{w} / \mathrm{c}$ ratio 0.40 there was not enough pore space to facilitate complete hydration of the cement particles, leading to reduced surface area, as has been reported in previous studies.

\subsection{Freeze-Thaw}

A summary of the freeze-thaw results as expressed in the relative dynamic modulus (RDM) and the percentage weight loss (PWL) is given in Fig. 5. The experimental data represent that the RDM of both the portland cement and $C \bar{S} A$ cement concretes with Limestone $\mathrm{G}$ had similar behavior through the duration of the test. The RDM of the concretes made with Limestone B diverged and the portland cement concrete was degraded more quickly. The RDM of the portland cement concrete dropped below $60 \%$ RDM at approximately 50 cycles, while that of the $C \bar{S} A$ cement concrete decreased below $60 \% \mathrm{RDM}$ at about 150 cycles.
According to ASTM C666, the test should be stopped when the RDM is below $60 \%$ because the samples became nondurable in a freeze-thaw environment. However, testing was continued until it was impossible to measure the RDM. The $C \bar{S} A$-B was terminated at 216 cycles because all of the samples had broken and could no longer be measured. Measurement of the PC-B was stopped at 144 cycles. Sample images of the concrete specimens at test termination are displayed in Fig. 6.

For the PWL in Fig. 5b, it was very little measurable differences among the four mixes until 144 cycles. The $C \bar{S} A$-B and PC-B had significant change of the PWL after 144 cycles due to large chunks of paste and aggregate separating from the samples. The PC-B lost the mass faster than the $C \bar{S} A$-B. The $C \bar{S} A-\mathrm{B}$ and PC-B showed a steady increase in PWL after 144 cycles due to surface scaling. The $C \bar{S} A-\mathrm{G}$ had lost $0.99 \%$ of its mass compared to the PC-G in which loss of the mass was $1.11 \%$. Therefore, PC-G lost $12 \%$ 


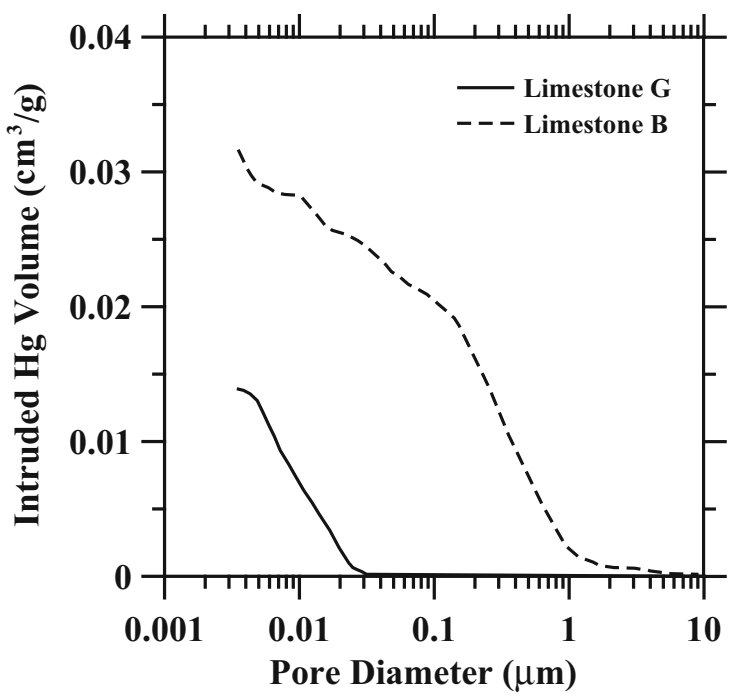

(a) Cumulative plot

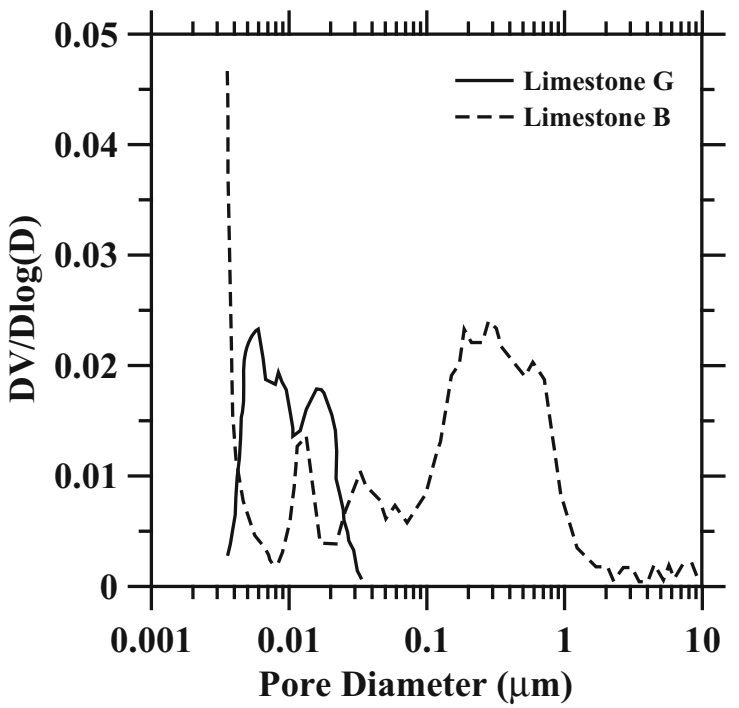

(b) Derivative plot

Fig. 3 Intruded $\mathrm{Hg}$ volume versus pore radius for concrete specimens.

Table 6 Nitrogen sorption analysis for $C \bar{S} A$ and portland cement pastes.

\begin{tabular}{|c|c|c|c|c|c|c|}
\hline \multirow[t]{2}{*}{$\mathrm{w} / \mathrm{c}$} & \multicolumn{3}{|c|}{$C \bar{S} A$} & \multicolumn{3}{|c|}{ Portland } \\
\hline & 0.4 & 0.5 & 0.6 & 0.4 & 0.5 & 0.6 \\
\hline $\begin{array}{l}\text { Pore volume } \\
\qquad\left(\mathrm{cm}^{3} / \mathrm{g}\right)\end{array}$ & 0.0848 & 0.0951 & 0.0725 & 0.0708 & 0.1216 & 0.1177 \\
\hline Surface area $\left(\mathrm{m}^{2} / \mathrm{g}\right)$ & 22.14 & 21.81 & 17.99 & 13.72 & 26.77 & 28.77 \\
\hline $\begin{array}{l}\text { Average pore } \\
\text { diameter }(\mathrm{nm})\end{array}$ & 14.97 & 16.86 & 16.12 & 19.03 & 17.44 & 15.93 \\
\hline
\end{tabular}

more of its mass than $C \bar{S} A-\mathrm{G}$ at the conclusion of the test. Images of the samples after 297 cycles are presented in Fig. 7.

For Limestone G, it is apparent that there is relatively little difference in freeze-thaw durability for both concretes with good aggregate and proper air entrainment. Both concrete batches would be considered freeze-thaw durable by maintaining a relative dynamic modulus greater than $60 \%$ through 300 freeze-thaw cycles. However, examining the specimens closely, it was observed that there was more scaling of surface material on the portland cement concrete samples than the $C \bar{S} A$ cement concrete samples. The loss of weight measurements for mixes PC-G and $C \bar{S} A-\mathrm{G}$ demonstrate that $C \bar{S} A$ cement concrete lost $12 \%$ less of its material due to scaling, even though there was relatively little difference in relative dynamic modulus. This should be of particular interest to transportation agencies because loss of weight measurements should be considered as selecting a durable concrete for a freeze-thaw environment, despite the fact that loss-of-weight is not explicitly called for in the ASTM C666 method.

For the mixtures with Limestone $\mathrm{B}$, both $C \bar{S} A$-B and PC-B failed to maintain at least $60 \%$ RDM before 300 cycles so that they would be considered not durable in a freeze-thaw environment. However, it is important to note that the aggregate used in this study has been anecdotally found to be unacceptable in a freeze-thaw environment and is never used in structural concrete exposed to freezing and thawing conditions. Based on the fact that the RDM of PC-B and $C \bar{S} A$-B dropped below $60 \%$ at about 50 cycles and at approximately 150 cycles, respectively, it is found that use of $C \bar{S} A$ has approximately $300 \%$ increase effect in the number of freeze-thaw cycles. There exist many aggregate types whose freeze-thaw quality is between Limestone B and Limestone $G$, and many of them are marginal quality for freeze-thaw environments. However, it is possible that while they could not be used in a portland cement concrete, they could possibly be used in a $C \bar{S} A$ cement concrete and pass a freeze-thaw durability test. These aggregates generally cost less than the better-performing aggregates, and they may be a huge economic advantage. Therefore, using $C \bar{S} A$ cement and marginal aggregates for concrete in a freeze-thaw environment may prove less expensive than portland cement concrete and higher quality aggregates.

\section{Conclusions}

A rapid-hardening calcium sulfoaluminate and portland cement were employed to investigate the porosimetric 


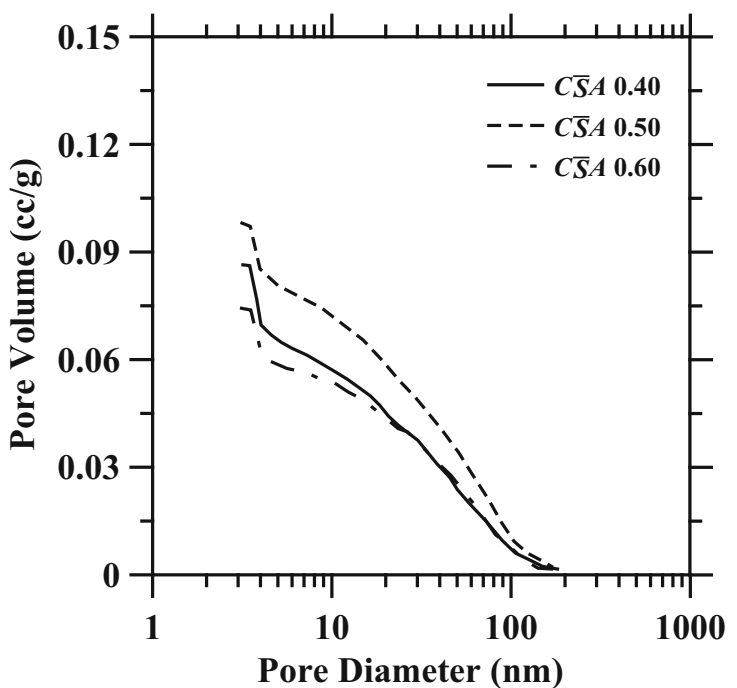

(a) $C \bar{S} A$ cement, cumulative plot

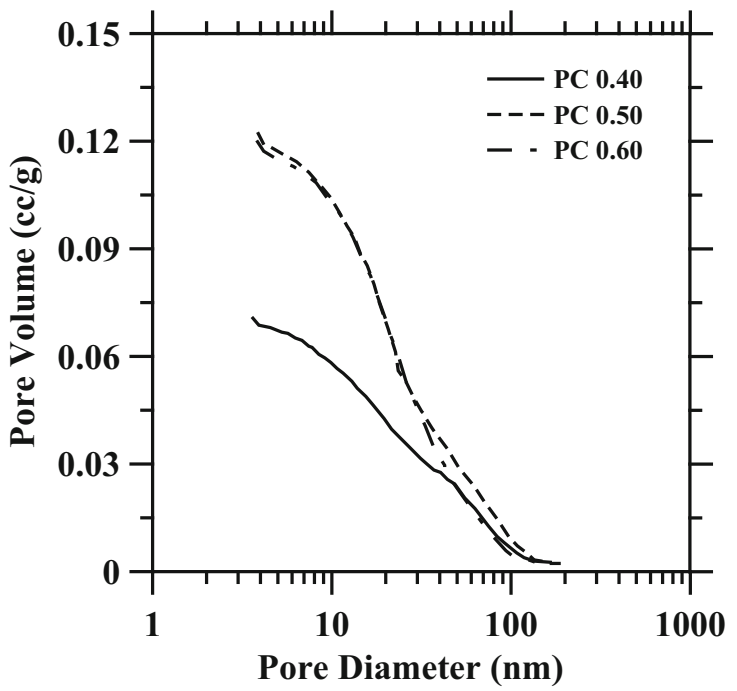

(c) Portland cement, cumulative plot

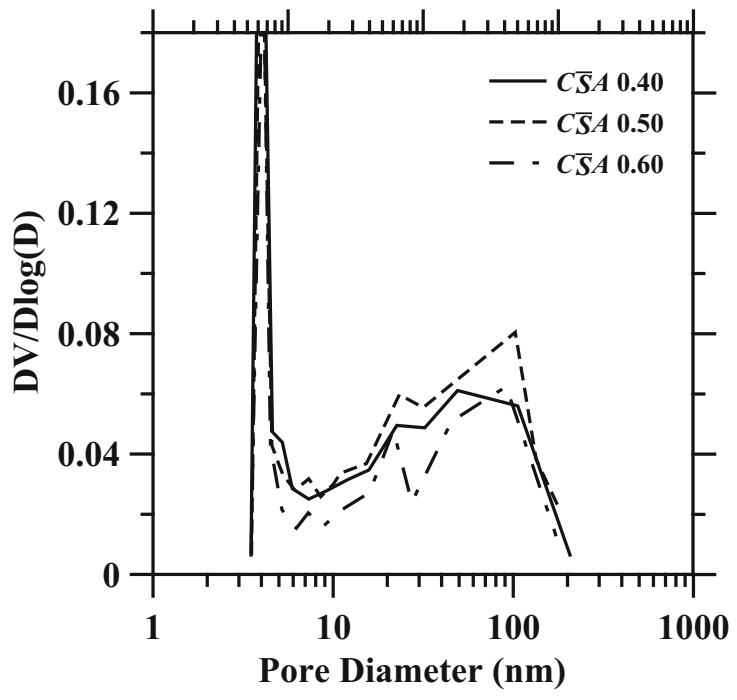

(b) $C \bar{S} A$ cement, derivative plot

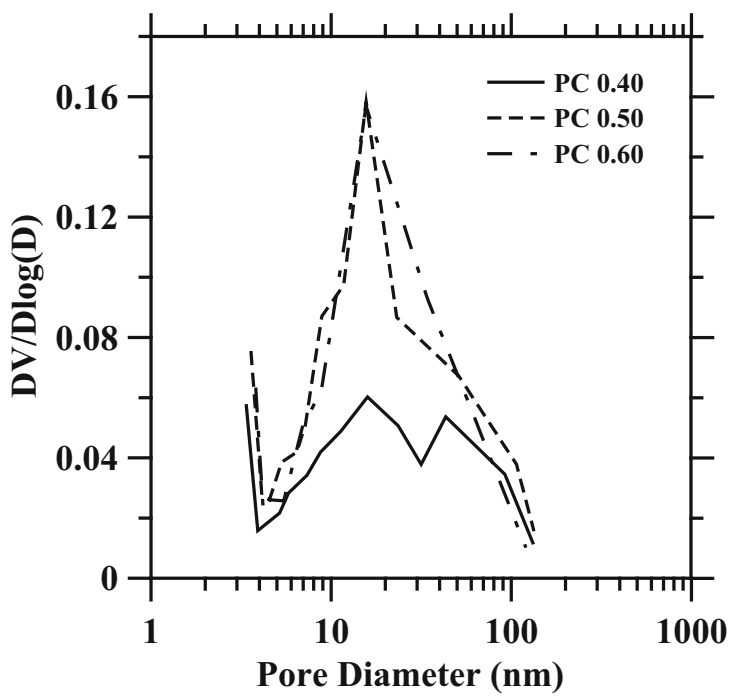

(d) Portland cement, derivative plot

Fig. 4 Pore size distributions measured by nitrogen desorption isotherms.

features of the cement paste and the durability of the concrete with two types of limestone. The pore volume and pore size distribution of the $C \bar{S} A$ and portland cement pastes were estimated by two methods: mercury intrusion and nitrogen sorption porosimetry. The relative dynamic modulus and percentage weight loss were measured for the durability of the concrete in a freeze-thaw environment in accordance with the ASTM C666. The following conclusions can be drawn.

1. Based on the analysis of the experimental results by specimen drying, mercury intrusion, and nitrogen sorption tests, $C \bar{S} A$ cement pastes have a smaller and coarser pore volume than portland cement pastes under the same w/c condition.

2. For mercury intrusion tests, a unimodal distribution was established for $C \bar{S} A$ cement pastes, while a bimodal distribution of pore size was displayed for the portland cement pastes. An increase in total volume of intrudable mercury with increasing w/c for both cement pastes was observed.

3. For nitrogen sorption, the total pore volume and pore size distribution were established by using desorption curve, the BET theory, the Harkins-Jura t-curve, and the $\mathrm{BJH}$ theory. Portland cement paste samples have a greater overall pore volume than the $C \bar{S} A$ cement pastes under the same $\mathrm{w} / \mathrm{c}$ ratio condition.

4. Air entrained $C \bar{S} A$ cement concrete in a freeze-thaw environment has approximately the same durability measured by RDM as air entrained portland cement concrete when coarse aggregate with good freeze-thaw durability was used.

5. When poor freeze-thaw aggregate was used, $C \bar{S} A$ cement concrete exhibits improved durability over portland cement concrete, increasing the number of ASTM C666 freeze-thaw cycles to failure by $300 \%$. 


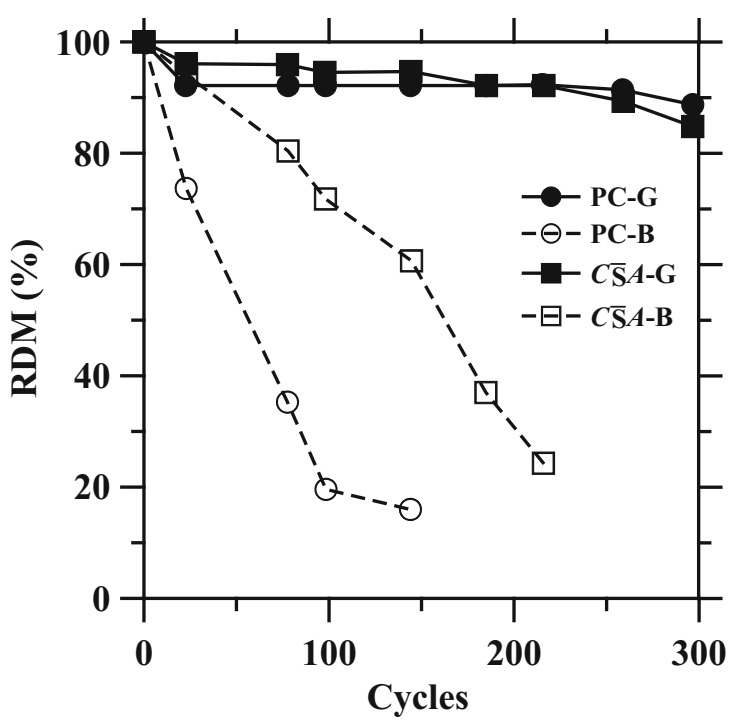

(a) Relative dynamic modulus

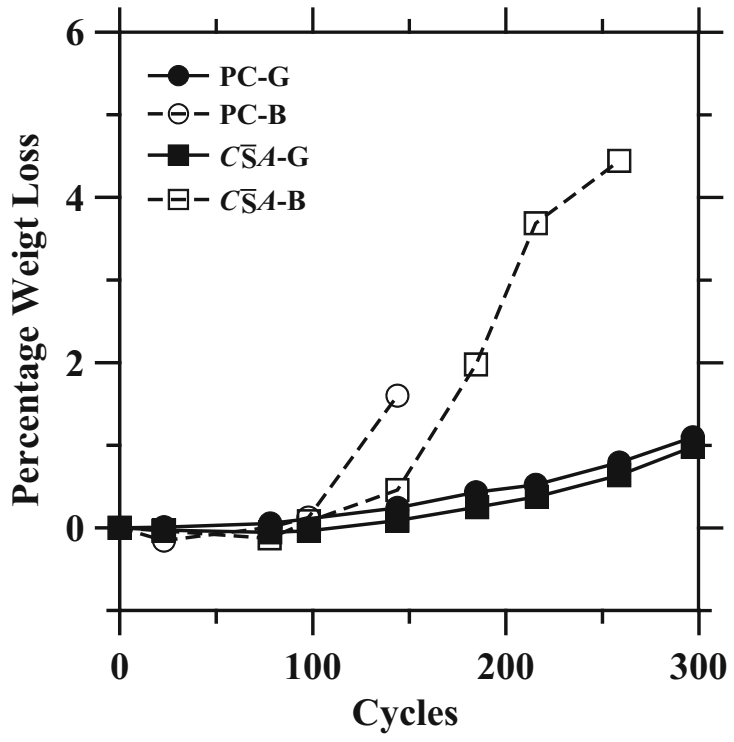

(b) Percent weight loss

Fig. 5 Experimental results for freeze-than test.

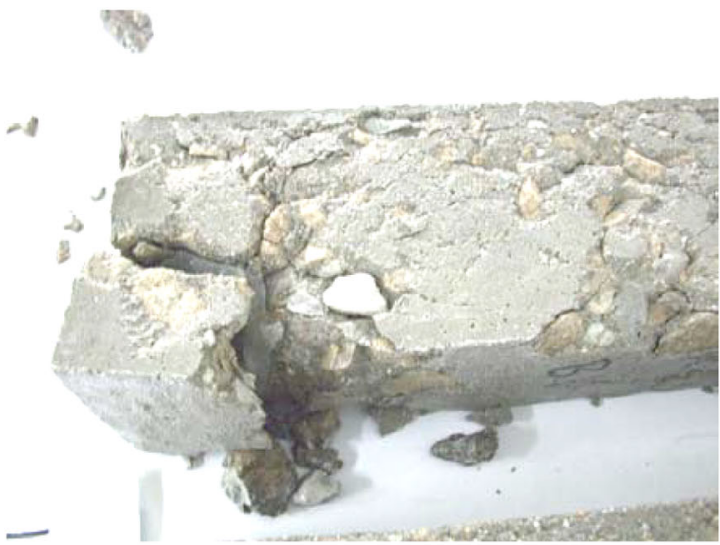

(a) Portland cement concrete with limestone B

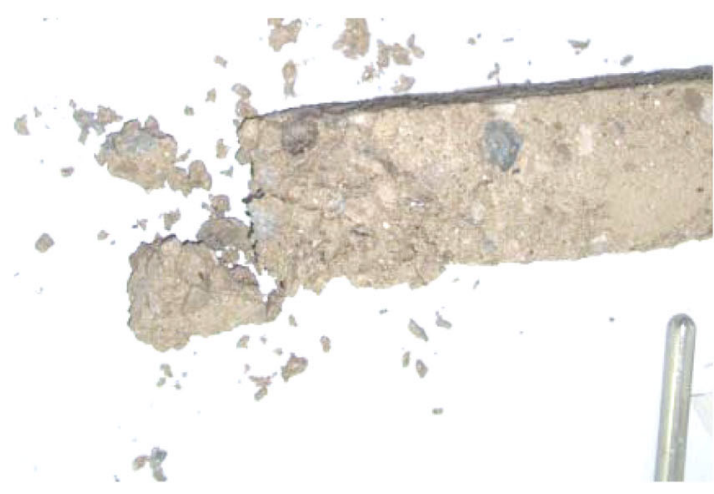

(b) $C \bar{S} A$ cement concrete with limestone $\mathrm{B}$

Fig. 6 Failure of specimens.

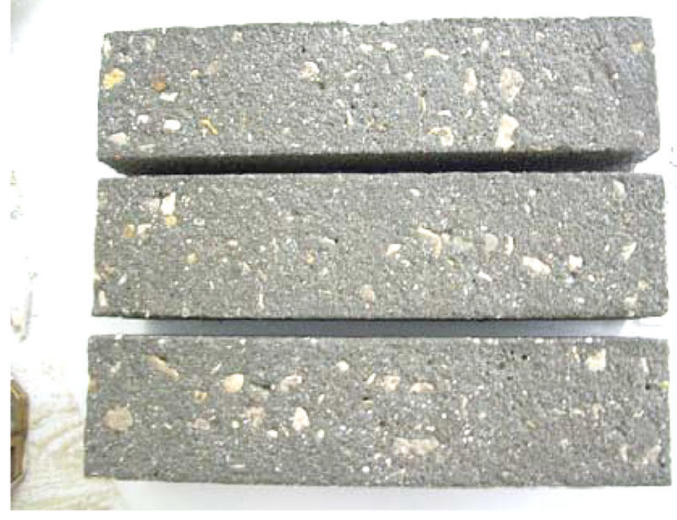

(a) Portland cement concrete with limestone G

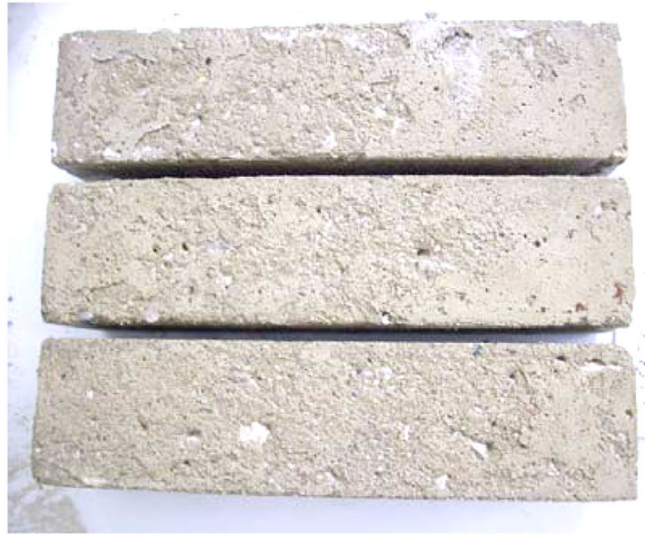

(b) $C \bar{S} A$ cement concrete with limestone $\mathrm{G}$

Fig. 7 Freeze-thaw specimen samples for portland cements with limestone $\mathrm{G}$ and $C \bar{S} A$ cement with limestone $\mathrm{G}$ (297 cycles). 
Moreover, $C \bar{S} A$ cement concrete exhibits less surface scaling in a freeze-thaw environment, losing $11 \%$ less mass after 297 cycles as good quality aggregate was used.

\section{Acknowledgments}

This research was supported by CTS Cement Manufacturing Corporation. Also, support from National Research Foundation of Korea Grant (2015-0001535) is gratefully acknowledged. The views expressed are those of authors, and do not necessarily represent those of the sponsors.

\section{Open Access}

This article is distributed under the terms of the Creative Commons Attribution 4.0 International License (http://creativecommons.org/licenses/by/4.0/), which permits unrestricted use, distribution, and reproduction in any medium, provided you give appropriate credit to the original author(s) and the source, provide a link to the Creative Commons license, and indicate if changes were made.

\section{References}

ASTM C109. (2002). Standard test method for compressive strength of hydraulic cement mortars (Using 2-in or [50$\mathrm{mm}]$ cube specimens). Philadelphia, PA: American Society of Testing and Materials.

ASTM C192. (2002). Standard practice for making and curing concrete test specimens in the laboratory. Philadelphia, PA: American Society of Testing and Materials.

ASTM C204. (2002). Standard test method of fineness of hydraulic cement by Air-permeability apparatus. Philadelphia, PA: American Society of Testing and Materials.

ASTM C215. (2002). Standard test method for fundamental transverse, longitudinal and torsional resonant frequencies of concrete specimens. Philadelphia, PA: American Society of Testing and Materials.

ASTM C666. (2002). Standard test method for resistance of concrete to rapid freezing and thawing. Philadelphia, PA: American Society of Testing and Materials.

Barrett, E. P., Joyner, L. G., \& Halenda, P. P. (1951). The determination of pore volume and area distributions in porous substances. I. Computations from nitrogen isotherms. Journal of the American Chemical Society, 73(1), 373-380.

Bernardo, G., Telesca, A., \& Valenti, G. L. (2006). A porosimetric study of calcium sulfoaluminate cement pastes cured at early ages. Cement and Concrete Research, 36, $1042-1047$.

Bondy, K. B. (2011). Use of shrinkage-compensating concrete in post-tensioned buildings - part two: a four-building survey. STRUCTURE Magazine, August, 27-29.

Brunauer, S., Emmett, P. H., \& Teller, E. (1938). Adsorption of gases in multimolecular layers. Journal of the American Chemical Society, 60(2), 309-319.

Cook, R. A., \& Hover, K. C. (1999). Mercury porosimetry of hardened cement pastes. Cement and Concrete Research, 29, 933-943.

Feldman, R. F., \& Sereda, P. J. (1970). A new model for hydrated portland cement and its practical applications. Engineering Journal of Canada, 53(8-9), 53-59.

Han, S. W., Kee, S.-H., Park, Y.-M., Lee, L.-H., \& Kang, T. H.K. (2006). Hysteretic behavior of exterior post-tensioned flat plate connections. Engineering Structures, 28(14), 1983-1996.

Harkins, W. D., \& Jura, G. (1944). Surfaces of solids. XII. An absolute method for the determination of the area of a finely divided crystalline solid. Journal of American Chemical Society, 66(8), 1362-1366.

Jennings, H. M., \& Tennis, P. D. (1995). Model for the developing microstructure in portland cement pastes. Journal of the American Ceramic Society, 77(12), 3161-3172.

Jeon, S.-J., Park, S. Y., Kim, S.-H., Kim, S. T., \& Park, Y. H. (2015). Estimation of friction coefficient using smart strand. International Journal of Concrete Structures and Materials, 9(3), 369-379.

Juenger, M. C. G., \& Jennings, H. M. (2001). The use of nitrogen adsorption to assess the microstructure of cement paste. Cement and Concrete Research, 31, 883-892.

Kang, T. H.-K., Wallace, J. W., \& Elwood, K. J. (2009). Nonlinear modeling of flat-plate systems. ASCE Journal of Structural Engineering, 135(2), 147-158.

Lee, J. D., Yoon, J. K., \& Kang, T. H.-K. (2016). Combined half precast concrete slab and post-tensioned slab topping system for basement parking structures. Journal of Structural Integrity and Maintenance, 1(1), 1-9.

Lowell, S., Shields, J. E., Thomas, M. A., \& Thommes, M. (2004). Characterization of porous solids and powders: Surface area, pore size and density. Boston, MA: Kluwer Academic Publishers.

Ost, B. W. A. (1975). Very High Early Strength Cement. U.S. Patent \#3,860,433.

Powers, T. C. (1958). The physical structure and engineering properties of concrete. Research Department Bulletin 90. Skokie, IL: Portland Cement Association.

Wittmann, F. (1977). Grundlagen eines modells zur beschreibung charakteristischer eigenschaften des betons. Deutscher Ausschuss für Stahlbeton, Heft, 290, 45-100.

Yang, K.-H., \& Kang, T. H.-K. (2011). Equivalent strain distribution factor for unbonded tendon stress at ultimate. $A C I$ Structural Journal, 108(2), 217-226. 